\title{
De la Matrona de Éfeso (A-Th 1510) a la compasiva viuda gallega
}

\author{
CAMINO NOIA CAMPOS \\ Facultade de Filoloxía e Traducción. \\ Universidade de Vigo
}

\section{RESUMEN}

El artículo hace un recorrido por la historia de las versiones documentadas sobre "la viuda infiel", desde la fábula latina de Fedro y la narración de Petronio en el Satiricón, pasando por las versiones medievales de los ejemplarios y de las colecciones fabulísticas, hasta las de tradición oral recogidas a partir del siglo XIX. Termina presentando un cuento oral en lengua gallega, desconocido por los investigadores internacionales y españoles del cuento folclórico.

Palabras clave: Fábula, Viuda, Misoginia, Versión, Tipo.

\section{SUMMARY}

The author reviews the history of the documented versions of the "The Unfaithful Widow" theme, from Phaedrus' Latin fables and Petronius' Satyricon through the Medieval exempla and collections of fables to the oral narratives published since the $19^{\text {th }}$ century. He finishes with a Galician folktale, unknown by international as well as Spanish students of folklore.

Key words: Fable, Widow, Misogyny, Version, Type.

Uno de los cuentos más difundidos en Europa desde el siglo I, en latín y después en lengua vulgar, es "La matrona de Éfeso", la viuda inconsolable que se deja seducir por un desconocido. Una historia misógina de carácter cómico-satírico documentada desde la literatura greco-latina en versiones de Esopo y de Fedro. Su origen remoto parece estar en Oriente, donde abundaron los cuentos sobre viudas infieles, y se documenta en la tradición budista (Uther 2004, tipo 1510).

RDTP, LX, 2 (2005): 149-164 


\section{VERSIONES ESCRITAS}

En la literatura greco-latina la primera documentación de esa historia la tenemos en una fábula de Fedro (siglo I), "Viuva et miles", de la que hay versiones en verso y en prosa.

Cuenta que una mujer, a la que se le había muerto el marido, llevaba cuatro días llorando desconsolada sobre su sepultura sin querer comer ni dormir. Cerca de allí, un soldado que vigilaba los cuerpos de dos crucificados, oyendo sus desesperados laméntos, se acercó a consolarla. La viuda rechaza varias veces sus efusivas muestras de afecto hasta que al fin acaba correspondiendo a sus deseos, y yace con él sobre la tumba del marido. Mientras tanto, alguien se lleva uno de los crucificados que el soldado tenía a su cargo, y al descubrir la falta éste se echa a llorar de rabia y desesperación por el castigo que le espera. Viéndolo así, la mujer le manda desenterrar el cadáver de su marido y colgarlo en lugar del crucificado.

Sin citar a Fedro ni la fuente de donde la había tomado, Petronio cuenta la misma historia protagonizada por una matrona de Éfeso en el Satiricón (60 d.C.), dentro del episodio de la "Cena de Trimalción" $(111,2)^{1}$. Y a partir de entonces la fábula se difunde por toda Europa bajo la autoría de Petronio.

Aunque no hay un criterio unánime sobre cual de los dos autores fue anterior, de sus obras se pueden extraer datos que dan la prioridad a Fedro. Ana María Duarte (1982), por ejemplo, ve en el relato del Satiricon referencias suficientes a Fedro para pensar que éste fue el primero en escribir la historia en latín. Sin hacer mención expresa al fabulista, dice Duarte (1982: 13-14) que Petronio alude a él a través del personaje de Eumalpo, el poeta narrador de la historia:

El poeta de Petronio, que lleva el apelativo de "tracio" y es émulo de Orfeo y Lino, odia a los ricos y escribe versos épicos. Curiosamente Fedro ataca también la debilidad del carácter femenino, afirma tener horror a las riquezas, compone ocasionalmente versos épicos y se dice "tracio" y sucesor de Orfeo y Lino. Todo ello puede inducirnos a pensar que Eumalpo en el cuento de Petronio podría muy bien ser la caricatura de Fedro.

Sin embargo la fuente de la historia latina se suele remontar a Esopo, de quien, supuestamente, Fedro toma sus fábulas. Ya en 1883, el erudito portugués Teófilo Braga (1995, II: 95) afirmaba que el creador de la his-

\footnotetext{
1 Petronio sitúa la historia en Éfeso, y en las fábulas de Fedro unas ves se habla de que sucedió en Éfeso y otras se omite el lugar como sucede en la versión de Rodríguez Adrados (1994: 151-152).
} 
toria, originada posiblemente en la ciudad asiática de Éfeso que "era como Mileto un centro de literatura erótica" ${ }^{2}$, había sido Esopo o un imitador suyo. Por su parte, Rodríguez Adrados (I, 1979 o 1994) sostiene que fueron los griegos los que inventaron el amor cómico, aunque ya en el origen de la fábula india, en el siglo II a. C., haya historias burlescas sobre la relación amorosa. Comedias de este tipo recorren la literatura griega, y en la época helenística reciben un tratamiento especial por influencia de los cínicos. Fueron escritores de ideología cínica, afirma Adrados, los responsables fundamentales del cruce de influencias entre los géneros fabulísticos griegos e indios. De manera que, ni Fedro ni Petronio son los autores de la historia de la viuda, sino que la tomaron de una fuente anterior.

Pero fuese o no Esopo el introductor de esta historia en la literatura occidental, la primera documentación que se conserva de sus fábulas está en el manuscrito conocido como "Apéndice" de la colección Accursiana ${ }^{3}$ del siglo IX. En este manuscrito hay una versión de la historia citada en la fábula "La mujer y el labrador", en la que el soldado y el robo del crucificado son sustituidos por un labrador y una yunta de bueyes. Esa misma versión se encuentra también en la Vida de Esopo ${ }^{4}$ del siglo X. Y si verdaderamente fue Esopo el primero en hacer la fábula, lo cierto es que Fedro y Petronio cambiaron la intención y los motivos.

La fábula de la "Accursiana" cuenta que una mujer que había perdido a su marido lloraba todo el día junto a su tumba. Al escucharla un labrador que araba con una yunta de bueyes cerca del cementerio, quiere yacer

${ }^{2}$ Braga (1995, II: 95-96) asienta la base oriental del cuento en la información del clérigo francés Longchamps, que en 1838 da noticia de un cuento semejante al de Petronio en un libro de cuentos indios: "Loiseleur des Longchamps, no Ensaio sobre as Fábulas Indianas e a sua introdução na Europa encontrou no Livro de Sindabad este conto desfigurado, e da-nos un quadro da sua tranmissâo desde o Oriente até ao século XVII: acha provavel que fosse uma lenda oriental, e segundo todos os indícios muito viajou, se considerarmos derivado desta fonte o conto chinês que o padre Du Holde traduziu em francês e publicou na Description Historique da la Chine. O grande sinólogo Abel de Remusant, também traduziu do chinês outra lição deste conto. $A$ Matrona de Éfeso indica a sua proveniência, relacionando-o com essa criação dos Contos Milesianos, que o génio grego tornou interessantes pela sua desenvoltura".

${ }^{3}$ La Accursiana es una de las numerosas colecciones fabulísticas que se hicieron en Bizancio de la colección Augustana (s. I a.C.), con la que culmina la tradición de la fábula antigua griega. La colección se llama Accursiana porque fue editada por Bonus Accursius en 1479 ó 1480 (Rodriguez Adrados 1979, I: 73; II: 261 y 1994:24; Chambry 1927: XXIX).

${ }^{4}$ Una vida novelada del fabulista griego que entrelaza fábulas, cuentos o simples anécdotas en la biografía. Se difundió en dos versiones bizantinas muy semejantes. La más antigua es del siglo $\mathrm{x}$. 
con ella y, dejando los bueyes en el campo, se acerca llorando a la viuda. Al verle tan apenado, la mujer le pregunta por qué llora y el labrador le dice que acaba de enterrar a su bella esposa. "A mi me pasa lo mismo", asegura la mujer. "Entonces deberíamos consolarnos juntos amándonos igual que hacíamos con nuestros esposos", responde el labrador. La mujer concuerda en que eso será lo mejor, y "el labrador disfrutó de ella" (dice la fábula). Mientras tanto alguien se lleva los bueyes del labrador, que al no encontrarlos llora de desesperación, lamentándose y golpeándose por su desgracia. Sorprendida ante el repentino cambio de humor, la mujer le pregunta por qué vuelve a llorar y el le responde: "Ahora lloro de verdad" "Ahora es cuando tengo que hacer el duelo", en la fábula de la Vida de Esopo) ${ }^{5}$.

Como se puede ver, esta fábula, además de mostrar el fácil consuelo de la mujer, dirige la moraleja final a criticar a los que fingen dolor para aprovecharse de la situación de otros ("el labrador disfrutó de ella"), una intención bien distinta de la misógina de la fábula latina. Y tal vez por la ausencia de crítica contra las mujeres o debido al enorme éxito del Satiricón que le dio notoriedad a la versión de "La matrona de Éfeso", la fábula de Esopo debió de ser poco conocida. De tal forma que es difícil encontrarla en las colecciones atribuidas al fabulista griego, ni en las medievales ni en las modernas. Lo cual contrasta con la frecuencia con que aparece "La viuda y el soldado" en los fabularios de Fedro.

Uno de los primeros autores en recoger la historia de "La matrona de Éfeso" en la Edad Media fue el clérigo inglés Juan de Salisbury. La incluye en su obra Policraticus ${ }^{6}$, que tuvo una gran difusión en Europa, y le dio actualidad a la historia como ejemplo de la conducta infiel y lujuriosa de las mujeres. De aquí parece tomarla Marie de France para su fable "La femme qui fist pendre sun barun" ${ }^{7}$, cuya sentencia final hace referencia

${ }^{5}$ La traducción al castellano de las versiones griegas es de Rodríguez Adrados (1994: 115-116 y 131-132).

${ }^{6}$ Policraticus sive de nugis curialium et vestigiis philosophorum, escrito entre 1115 y 1180 , es un retrato intelectual del pensamiento y de la vida política del siglo xII. En el prólogo, dice Salisbury que lo hace para lectura de príncipes con el fin de instruirlos sobre la función que deben ejercer; y así mismo para los educadores, los jueces y cada uno de los estamentos que componen una sociedad organizada. El cuento de "La matrona" está en el capítulo 11 del Libro VIII, en los párrafos dedicados a la pasión carnal, donde el autor glosa los postulados misóginos de San Jerónimo (Salisbury 1984: 677).

${ }^{7}$ En su edición de las Fables de Marie de France, Brucker (1998:133) cita un estudio de H. R. RuNTE, "Alfred's Book, Marie de France and the Matron of sphesus" (Romance Philology, 36, 1983, pp. 556-564) en el que dice que la fuente directa de la escritora medieval sería el pasaje del Policraticus de Salisbury que relata la historia 
al respeto que se debe a los muertos. De mediados del siglo XII hay también un Novellino italiano con la historia de una viuda infiel, en la que se exagera la lujuria y la barbarie de la mujer, haciendo que ella misma cuelgue de la horca el cadáver del marido y le haga una herida en la cara para que se parezca al cadáver del ahorcado (Frenzel 1976: 486).

La historia de la viuda infiel pasó enseguida a los ejemplarios medievales como modelo de la falsedad de las mujeres. Ya en el siglo XIII se encuentra en la famosa Historia Septem Sapientium Romae y entre los exempla de Jacques de Vitry y de Etienne de Bourbon ${ }^{8}$. Y en el siglo XIV es tema de un exemplum de la Scala Coeli del dominico francés Jean de Gobi ${ }^{9}$.

Al mismo tiempo que los ejemplarios y fabularios se servían de la historia de la viuda de Éfeso para afear el comportamiento de las mujeres, en otras modalidades genéricas fueron apareciendo nuevas versiones con la misma finalidad. Del siglo XIII es el fabliau "Cele qui se fist foutre sur la fosse de son Mari, ${ }^{10}$, que cuenta una historia con motivos más acordes con la sociedad medieval, incrementando la lujuria de la mujer. Y si aceptamos la teoría de Joseph Bédier (1969: 19) ${ }^{11}$, defensor acérrimo del origen popular de los fabliaux, habrá que pensar que la historia procede de una versión oral, de donde la tomaría el clérigo que la escribió con

de la Matrona de Éfeso tomada, a su vez del Satiricón, o de una de las colecciones fabulísticas de Fedro o Romulus.

${ }^{8}$ La Historia Septem Sapientium Romae, escrita por un monje de la abadía francesa de Haute Selve, contiene relatos de origen diverso, cuatro proceden del Sendebar y los otros de varias tradiciones occidentales. De esta obra, muy difundida por Euro$\mathrm{pa}$, se hicieron numerosas traducciones a todos los idiomas europeos con cambios notables entre ellas y con respecto al original. Los exempla de Jacques de Vitry están en los Sermones feriales et communes y los de Etienne de Bourbon en el Tratactus de diversis materiis (Cf. ThEMA).

9 Scala Coeli es un amplio ejemplario compuesto por cerca de mil exempla, distribuidos en 122 rúbricas ordenadas alfabéticamente, que fue escrito entre 1327 y 1330 .

${ }^{10}$ Un siglo antes, Marie de France permanece fiel a la versión latina en su fable.

${ }^{11}$ Para él "Fabliaux, farces, nouvelles italiennes ne sont que les accidents littéraires de l'incessante vie populaire des contes. Il est peut-être utile de comparer entre elles ces diverses manifestations littéraires. Mais il est permis aussi de considérer les fabliaux comme des oeuvres non pas adoptives, mais exclusivement françaises; et de même les nouvelles de Sercambi ou de Bandello, sans se préoccuper de leurs sources, comme des oeuvres exclusivement italiennes. - Cette conception est fausse peut-être, —négative, non pas" (Bédier 1969: 19). En su estudio sobre literatura medieval, Per Nykrog (1957: 145) presenta este fabliau como prueba de perfección estilística. Dice que es una historia bien contada en la que se suceden las escenas manteniendo la intriga y de forma divertida. 
una intención claramente misógina. El fabliau lleva una introducción en primera persona, en la que el narrador anuncia que no va a contar una fábula sino una verdad sucedida en Flandes; y, a modo de moraleja, afirma: "La mujer es siempre muy propensa a llorar y a mostrar gran duelo cuando se encuentra una pequeña contrariedad. Pero enseguida olvidará su pena" (López Alcaraz 2003: 181-183).

Se cuenta en el fabliau que un hombre rico deja viuda a una joven que llora desconsolada sobre su tumba sin querer apartarse de allí. Un caballero desconocido, acompañado de un escudero, pasa cerca de la mujer y viéndola tan apenada se lamenta de su dolor ante la burla del criado, que le asegura que el llanto es fingido como le demostrará enseguida. Aún insistiendo en la sinceridad de la dama, el caballero accede a esconderse para observar a su escudero. Éste se acerca a la mujer diciéndole que ha matado a su esposa de tanto que la jodió (en foutant), y la viuda le pide que la mate también a ella de la misma forma. A lo que gustosamente accede el escudero ante el asombro del amo.

En el siglo XV Diego Cañizares publica su Novella ${ }^{12}$ en la que relata en castellano quince ejemplos tomados de la Scala Coeli, y entre ellos aparece una nueva historia de una viuda. Esta primera versión en castellano de la viuda contiene elementos que separan el relato de la fábula latina. Cuenta que una viuda, ante la promesa de matrimonio de un joven a quien acaba de conocer, desentierra el cadáver del esposo para ponerlo en la horca en lugar del cuerpo robado, y para darle un mayor parecido con el ahorcado le hace un corte en la cabeza. Ante tal crueldad, el joven caballero la desprecia y renuncia a casarse con ella.

Las semejanzas entre esta versión y la del novellino italiano muestra que una nueva historia circulaba por Europa, por lo menos, desde hacía tres siglos. El motivo de la mutilación del cadáver se atribuye a un cuento chino que debió mezclarse con la fábula latina dando lugar a nuevas versiones. El cuento chino podría ser el que cuenta Espinosa (1947, II: 361-364) con el título de "La dama del abanico". Una historia semejante a la de Cañizares con una supuesta viuda que omite el motivo del ahorcado y que, desde una versión francesa, se difunde por Europa a partir del siglo XVIII ${ }^{13}$. Basándose en los datos de Eduard Grisebach (1889), Espinosa cree que el cuento chino más antiguo es la leyenda de Chuang Song,

${ }^{12}$ El título completo es Novella que Diego Cañizares del latín en romançe declaró y transladó de un libro llamado Scala Çeli (Versiones castellanas 1949). El cuento citado está en Lacarra 1999: 101-103.

${ }^{13}$ Voltaire utiliza la historia china en el segundo capítulo de Zadig (1747), "Le nez". Y Emilia Pardo Bazán la reelabora en el cuento "El agravante». 
discípulo de Lao Che, que vivió en el siglo IV. Una larga historia en la que hay dos viudas, una auténtica y otra supuesta. Ésta, cuando va a abrir la caja del cadáver de su marido para quitarle los sesos y curar la enfermedad del joven que le ha prometido matrimonio, ve llorar al marido y lo ayuda a levantarse. Al darse cuenta de lo sucedido, la mujer queda $\tan$ avergonzada que se ahorca. Y el marido, desesperado, le prende fuego a la casa donde ambos habían vivido felices.

A diferencia de las fábulas greco-latinas, este cuento, basado en antiguas tradiciones de Oriente, es una historia trágica. Espinosa (1947, II: 365) deduce que debió sufrir cambios al mezclarse con la historia de "La matrona de Éfeso", dando origen a nuevas versiones en las distintas lenguas europeas, con motivos que no están en el Satiricón. De todas formas, como en la tradición oral de Occidente, en China hay otros cuentos sobre viudas; en unos el marido está muerto de verdad y en otros finge morirse para poner a prueba a su mujer. Versiones de los dos tipos debieron de circular por Europa.

Paralelamente a las nuevas versiones que se fueron elaborando, la fábula latina siguió apareciendo en las colecciones fabulísticas europeas ${ }^{14}$, en textos literarios y en tratados didácticos, como ejemplo del falso comportamiento de las mujeres, hasta el siglo XVIII. Está documentada en un Fabulario Português del siglo XV, traducido de la colección Esopo-Romulus vulgaris ${ }^{15}$, con el título de "A viúva e o alcaide", con una moraleja final en la que se advierte de la falsedad de las mujeres. En versos endecasílabos la recoge el Romancero general de Miguel de Madrigal, en 1605, como "Carta contra los vicios de las mujeres" (Chevalier 1982: 217-218). Y aparecen dos breves versiones portuguesas en obras del siglo xviII: Hora de Recreio nas Férias de Maiores Estudos del Padre João Baptista de Castro y Divertimentos de estudosos del Marqués de Soares (Braga 1995, II: 94-95). Elisabeth Frenzel (1976: 486-487) da referencia de obras francesas, inglesas y alemanas que reelaboran la historia de la viuda.

${ }^{14}$ Desde la época imperial las fábulas latinas fueron libros escolares. En el siglo IV, Donato anima a leerlas por su valor pedagógico en sus Ars minor y Ars mayor. Lo cual contribuyó a la enorme difusión que tuvieron las fábulas en toda la Edad Media. Las colecciones de Rómulo y Aviano, junto a las de Esopo, fueron las más populares y leídas en las escuelas medievales (Curtius 1976, I: 79-87).

${ }^{15}$ El manuscrito se conserva en la Biblioteca de Viena (antigua Biblioteca Palatina). En 1903 Leite de Vasconcelos publicó una edición en la Revista Lusitana, que el dirigía. 


\section{VERSIONES ORALES}

La fábula latina como ejemplo de la lujuria e infidelidad de las mujeres, utilizada en el púlpito por los clérigos, llegó a las gentes iletradas que la trasformarían en cuentos con motivos más acordes a las costumbres de las antiguas comunidades rurales, difundiéndolos por vía oral a través de sucesivas generaciones.

La versión oral más conocida en la Península Ibérica sobre el tema de una viuda es "La falsa esposa", que cuenta como un labrador, que se vanagloriaba de lo mucho que lo quería su mujer, pretende demostrárselo al criado, que se burlaba de él diciéndole que la mujer fingía amarlo. Se hace el muerto con la complicidad del criado, quien le lleva la noticia a la esposa. Ésta se echa a llorar con desesperación, pero al poco rato decide preparar la cena. Ama y criado acuerdan no comunicar a los vecinos la muerte del hombre y velar solos el cadáver. Después de comer y beber abundantemente, el criado se acerca a la mujer con grandes muestras de cariño; y esa misma noche ella se compromete con él en matrimonio. El marido, que había observado todo, se levanta furioso del ataúd y comienza a palos con su mujer.

El cuento parece haber tenido gran difusión en la tradición oral de muchos países a juzgar por el amplio número de referencias de Uther (2004, tipo1350). Aparece en castellano en 1589, en el tratado de moralidad Diálogos familiares de la agricultura cristiana de Juan de Pineda con el título "Muérete y verás". Lo recoge Teófilo Braga ${ }^{16}$ (1995, I) en el siglo XIX en el Algarve, incluyéndolo en su colección de cuentos tradicionales portugueses con el título de "Alegria da viúva", y Aurelio Espinosa (1946: I) en la provincia de Ávila. Según las referencias del Index tipològic de la rondalla catalana (Oriol y Pujol 2003, tipo 1350) el cuento aparece también en Castellón, Valencia y Mallorca. Esperamos la publicación del volumen correspondiente a los cuentos jocosos españoles de Camarena y Chevalier para conocer la extensión completa del cuento en la Península.

En la Literatura popular del País Vasco, publicada en 1935 por Resurrección $M^{\text {a }}$ Azkue (1989), hay una historia semejante a la de "La esposa

${ }^{16}$ Está en el volumen I de Contos tradicionais do povo português (1883). En las colecciones anteriores de cuentos portugueses, Contos e bistorias de proveito e exemplo (1585) de Fernandes Trancoso y Contos populares portugueses (1879) de Adolfo Coelho, no hay versiones de este cuento. El libro de Trancoso, escrito con una finalidade moralizante, contiene historias tomadas fundamentalmente de textos escritos. Isabel Cardigos da referencias de un buen número de versiones portuguesas del cuento en el Índice dos contos tradicionais portugueses (inédito). 
falsa", "Biziak ezagutzeko" (Para conocer a los vivos, morir"). Pero ésta, en lugar de criticar la infidelidad de la mujer, parece dirigir la críticas contra el matrimonio obligado ${ }^{17}$.

Tampoco tengo referencias de versiones francesas de cuentos sobre viudas. Habrá que esperar a la publicación de los últimos volúmenes de Le conte populaire français (Delarne y Ténèze 2002), para comprobar si existen.

\section{El CUENTO GALLEGO}

En la tradición oral gallega no tenemos versiones semejantes a "La esposa falsa" pero, en cambio, es muy conocida la historia de la viuda que refiere el fabliau. Todavía el año 2000 pude grabar una versión, "Os homes e a mula" (Noia 2002), a una señora de setenta y ocho años en la provincia de A Coruña, de esa historia:

Unha vez eran dous homes. E iban de camiño por unha aldea. Un levaba unha mula.

E estaban sacando un defunto da casa e a muller desía:

- iAi, Manuel, que pena tan grande teño! ¡Ai, meu homiño querido, que vou faser sen ti

Entonses dixo un dos homes, o que levaba a mula:

-iA pobre da muller ten boa pena!

E díxolle o outro:

- Qué xoghas e esta noite vou durmir eu con ela.

-iQue dis, ho!

- ¿Xógha-la mula?

E díxoll'el:

-iXogho, ho!

- iTa feito!

A pola noite, o home foi petar na porta da viuda e díxolle:

- ¡Ai, muller! ¿Non terá un sitiño pra pasa-la noite? Sonlle de lonxe e mañán teño qu'ir a Noia.

- ¡Non, home, non teño! sólo teño a miña cama.

— ¿E podo quedar aquí na cuciña? ¡Mellor que sen tellado...!

Dixo:

-Bueno..., pois se está conforme con eso...

E cando estaba deitado na cusiña, empeza o home:

— ¡Burrrb, burrrb! ¡Ai, que friaxe vai!

${ }^{17}$ Está recogida en Olaeta (Biscaia). Las variantes que presenta respecto a las anteriores son que el hombre finge morirse para comprobar si su mujer, que no le demuestra ningún afecto, le quiere o no; y comprueba que lo desprecia, incluso muerto. Y tampoco hay infidelidad, aquí el hombre le pega a la mujer por el maltrato que recibe de ella. 
E díxolle ela:

- ¡Ai, home! ¿e logo ten moito frío?

-iTeño, teño, teño moitísimo frío, burrrb!

- ¡Bueno, pois veña logho para aquí, pón ladiño da cama!

—iAi non! ¡Burrbbb, burrbbb! Non a quero molestar.

- ¡Veña, home, veña logo paquí!, non vaia enfermar co frío.

E vai a muller e meteuno na cama, pero ela separouse del e púxose nunha esquina da cama. E el seguía dicindo:

-iAi, que frío! ique frío tan grande teño!

-Pois achéghese, home, achéghese algho máis pra aquí.

E o home foise acheghando a ela e, claro, deulle a tentación e (...). E a muller, entón, dixo:

- ¡Ai, meu homiño! ¡Ai, meu homiño, que pronto ch'olvidei!

E o amigho, o home da mula que estaba escoitando o que fasían, dixo:

-iAi, puta, e perdín a mula!

Esta versión vino a sumarse a otras cuatro ya publicadas ${ }^{18}$, a las que debemos añadir una literaria, escrita por nuestra poetisa Rosalía Castro (1837-1885), en 1864, con el título de "Conto gallego" ${ }^{19}$.

La localización de cinco versiones orales con los mismos motivos en diferentes provincias gallegas, el tratamiento literario en el siglo XIX y que todavía hoy se pueda encontrar en la memoria de algunas personas, nos hace pensar que el cuento debió gozar de gran popularidad en Galicia, por lo menos durante dos siglos. Y no deja de extrañarme el hecho de no haber hallado versiones semejantes en otras áreas lingüísticas de la Península.

La semejanza entre la historia de nuestro cuento y la del fabliau parece indicarnos que la fuente está en el texto francés del siglo xIII. Las dos historias tienen los mismos motivos, y hay sólo pequeñas variantes entre ellas. En ambas historias:

${ }^{18}$ Tres aparecen en antologías de cuentos folclóricos: "Aventura de dous arrieiros" en Contos populares da Galiza de Leandro Carré Alvarellos (1968); "Xogar a mula por unha viuda" en una pequeña antología de cuentos de la provincia de Ourense de Fernández Insuela (1993:175-176), y "O macho e a viuda" en la de cuentos de Ibias (Asturias) de Fanny López Valledor (1998). La cuarta versión fue grabada en 1978 por la musicóloga suiza Dorothy Schubarth en una aldea del ayuntamiento de Vicedo (Lugo), y está publicada en un artículo de Carme Ríos Panisse (2000).

19 El "Conto Gallego" se volvió a publicar en 1923, en la revista Almanaque Gallego de Buenos Aires, y en 1946 en Cuadernos de Estudios Gallegos (Bouza Brey 1946). A partir de entonces el cuento de Rosalía fue objeto de varios estudios: Carballo Calero (1975), M ${ }^{a}$ Luz Casal (1976), Carme Carro (1984), Francisco Rodríguez (1988) y Ríos Panisse (1995 y 2000). El descubrimiento de un folleto con dos cuentos titulado Contos da miña terra (1864) en los fondos de la Real Academia Galega, por la profesora Carme Ríos Panisse (1995), aportó nuevos datos que confirmaron la autoría de Rosalía de Castro. 
a. La mujer llora sobre el ataúd del esposo el día del entierro.

b. Dos hombres que van de camino presencian el llanto de la viuda. Uno se apiada al verla tan desconsolada y el otro se burla de él.

c. Este último pretende demostrar que el llanto de la viuda es falso utilizando una argucia para acostarse con ella.

d. La estrategia da resultado y la viuda acaba haciendo el amor con el desconocido ante el asombro del compañero, que, en el cuento gallego, pierde la apuesta.

La diferencia fundamental entre el fabliau y el cuento gallego está en la lujuria con que se describe a la mujer en la versión francesa, que contrasta con nuestra cándida protagonista, quien acaba uniéndose al desconocido con una actitud entre caritativa y pasional, al no poder evitar la proximidad del varón. Además, en el cuento gallego los hombres apuestan una mula (u otro animal) y en el fabliau no hay apuesta, aunque el escudero hace referencia a ella.

Los cambios entre la historia latina y la nuestra se explican como adaptaciones necesarias para la recepción del cuento en la sociedad rural. De ahí que en el cuento gallego el lugar de encuentro del desconocido con la viuda sea la casa y no el cementerio, un lugar sagrado, donde la católica sociedad gallega desaprobaría que se realizase una relación sexual. El tránsito de arrieros que observan la vida de la comunidad era algo muy común en las antiguas aldeas y, finalmente, la apuesta de los dos hombres en defensa de la mujer le da a la historia un tono divertido, al comparar irónicamente a la mujer con la mula. El cuento gallego es un relato verosímil con una intención más jocosa que misógina. Con el comportamiento de la viuda quizás nuestras contadoras gallegas quisiesen llamar la atención sobre la falta de libertad de las mujeres casadas, obligadas a guardar fidelidad al marido incluso después de muerto. Esa intención crítica contra la institución matrimonial es la que se desprende de la versión del cuento de Rosalía Castro.

Que la historia de un fabliau se haya instalado en territorio gallego y conservado en la tradición oral es fácil de entender si pensamos en los numerosos peregrinos franceses que vinieron a Compostela desde los albores de la Edad Media. Cuántos cuentos habrán contado durante los días de viaje en las casas y posadas donde pernoctaban. El intercambio de historias y canciones entre peregrinos y gentes de los lugares por los que pasaban debió ser inmenso. Lo que me sorprende es que el cuento francés se haya instalado exclusivamente en el área lingüística del gallego, si para llegar a Santiago los peregrinos tenían que recorrer cientos de kilómetros por tierras navarras y castellanas. 
Una posible explicación de los límites del cuento a una única área lingüística nos la da el folclorista belga Roger Pinon (1965: 33-34). Partiendo de la idea de que el cuento oral tuvo "una transmisión continua en el tiempo y en el espacio, con detenciones y olvidos", propone tres supuestos que explican el funcionamiento del proceso de circulación de las versiones de un mismo cuento: 1 . Si se trata de una recreación tardía del tipo, la versión o subtipo se limitará a una sola región. 2. Si la versión se extiende por varias zonas vecinas, se deberá a que la trasmisión partió de una de las regiones. 3. Si la versión está documentada en varios lugares sin contacto entre sí, o en un mismo país en épocas diferentes, hay que recurrir a la teoría de los estratos superpuestos.

Y dado que nuestro cuento es "privativo de una sola región" (utilizando la frase de la traducción argentina), debemos suponer que se trata de una recreación tardía del tipo que entraría en Galicia con bastante posterioridad a la Edad Media, por lo cual no se extendió a otras áreas lingüísticas.

Esta hipótesis parece la más verosímil, y si hubiese referencias de alguna versión semejante en la tradición oral francesa, la aceptaría sin más. Sin embargo, hasta que los datos del catálogo francés nos den referencias del cuento, me atrevo a proponer otra hipótesis: que nuestro cuento se originase en el área lingüistica del gallego a partir de la fábula latina - o griega-, de la viuda infiel, difundida por los clérigos en el púlpito. De Galicia lo podría haber llevado a Francia en la Edad Media el clérigo que lo puso en verso en el fabliau con una intención claramente misógina. $\mathrm{Y}$, posiblemente, debido a la obscenidad del relato francés y a la fama que todavía tenía en el siglo XIII la fábula de la "viuda de Éfeso", el cuento tuvo poca difusión.

\section{TIPOS DEL CUENTO}

Aurelio Espinosa (1947: II, 355-367), que dice conocer un buen número de versiones sobre la mujer infiel en toda Europa, no alude al cuento gallego ni al fabliau. Con las versiones europeas, que según él "son legión", hace dos grupos. Uno para los cuentos en los que el esposo, oculto en la casa, sorprende a su mujer con un amante, y en otro, que el llama "el general de la Matrona de Éfeso", para los protagonizados por una viuda, falsa o verdadera.

Pero hay otro grupo especial del cuento de la mujer infiel en el cual el marido, para probar la fidelidad de su mujer, finge la muerte, y descubre que la que tan gran amor y fidelidad le protestaba está dispuesta a casarse con el criado o amigo del marido inmediatamente después de la fingida muerte del marido. A este 
grupo general y más intrigante del cuento pertenecen nuestra picaresca y graciosa versión española 93, la portuguesa de Braga arriba citada y alguna otra versión moderna y también algunas versiones del popularísimo y celebérrimo cuento de la Matrona de Éfeso, tan graciosamente contado por Petronio en su Satyricon, y con mucha más gracia y perfección artística en las versiones chinas que vamos a examinar (Espinosa (1947, II: 357).

Curiosamente Espinosa, como había hecho Braga (1995, I: 202) ${ }^{20}$, mete en el mismo grupo los tres cuentos: "La esposa falsa", "La matrona de Éfeso" y el cuento chino.

Con mejor criterio, Antti Aarne y Stith Thompson, en The Types of the Folk-Tales, y Hans-Jörg Uther, en la revisión del catálogo ${ }^{21}$, marcan una clara diferencia entre los cuentos en los que el marido finge morirse y los de "La matrona de Éfeso", asignándoles tipos diferentes. El 1350, The Soon-Consoled Widow, en la sección "Cuentos acerca de matrimonios", a los primeros, y el 1510 The Matron of Ephesus (Vidua), a aquellos que se mantienen próximos a la versión latina. Tampoco los catálogos citados hacen referencia a la versión del fabliau ni al cuento gallego.

En el Catálogo tipológico de cuentos floklóricos aragoneses, González Sanz (1996) ilustra el tipo 1350 con el cuento "iApartadlo del castaño!", coincidente sólo en el motivo principal [H466], "Un hombre finge la muerte para probar la fidelidad de su mujer", con el de "La falsa esposa", del que se distancia en el resto. En la versión aragonesa, muy conocida en el área lingüística del gallego (Prieto 1958: 14, Lugo 1963: 97-98, Carré 1968: 139, Noia 2002: 285), el marido finge la muerte hasta que lo llevan al cementerio; en el camino sale de la caja agarrándose a las ramas de un árbol. Y cuando éste se muere de verdad, la mujer le pide a los que lo llevan al cementerio que no pasen por debajo del árbol. Entre las dos historias hay distancia suficiente para marcar la diferencia entre ellas. Así lo consideró Uther (2004) proponiendo el subtipo $1354 \mathrm{C}^{*}$ para las versiones de la historia "iApartadlo del castaño!n.

¿Y en que tipo incluimos el cuento "Os homes e a viúva"? En trabajos anteriores (Noia 2002 y 2004), atendiendo a la relación que establece Bédier

${ }^{20}$ Braga (1995, I: 202) dice: "é uma forma popular da antiga tradição da Matrona de Éfeso, tão frecuentemente citada nos escritores clássicos".

${ }^{21}$ The types of international folktales. Helsinki: Editorial Staff, 2004. También los diferencia Frederic Tubach (1981).

22 Bédier (1969: 462), aportando argumentos a su propuesta del origen oral de las historias de los fabliaux, cita el de "La Femme au tombeau" y dice: "Ce récit est apparenté au conte de la Matrone d'Éphese. Pour toutes les references, voyez les éditions diverses du livre de Griesenbach, Die Wanderung der Novelle von der treulosen Wittwe durch die Welliteratur. On y trouvera une très riche collection de variantes, et 
entre el fabliau $^{22}$ y la fábula latina, lo asignado al tipo 1510 de A-Th puesto que, pese a la distancia entre nuestro cuento y el de "La viuda de Éfeson, los dos tienen el mismo tema y están protagonizados por el mismo personaje, una viuda desconsolada que, seducida por un desconocido, acaba teniendo relaciones sexuales con él.

\section{CONCLUSIÓN}

El largo recorrido por la historia de las versiones de la viuda infiel nos lleva a estas conclusiones: que la introducción en Europa del cuento chino debió influir en la creación de nuevos cuentos como "La falsa esposa", de gran vitalidad en la oralidad; que el origen del cuento gallego "Os homes e a viuda", en el que no se aprecian influencias del relato chino, puede estar en una temprana reelaboración de la fabula latina $\longrightarrow$ de la griega - en Francia o en Galicia. Y, finalmente, que la versión del esposo que finge morirse y se agarra a la rama de un árbol en el trayecto al cementerio, es una variante del tipo 1350 , catalogada por Uther (2004) con el subtipo $1354 \mathrm{C}^{*}$.

Y si, como afirma Espinosa (1947, II: 61) "23 "la versión de Petronio no es la fuente inmediata de todas las versiones occidentales" de cuentos de viudas, y hay fuentes más antiguas en la literatura china "que conservan con mayor fidelidad los elementos fundamentales de la verdadera versión oriental primitiva", habrá que deducir que los cuentos gallegos proceden de una fuente oriental.

\section{BIBLIOGRAFÍA CITADA}

Aarne, ANTti y STITH ThOMPSON. 1981. The Types of the Folktale. A Classification and Bibliography. FF Comunications. Vol. LXXV, n.o 184. Helsinki: Suomalainen Tiedeakatemia/ Academia Scientiarum Fennica, 1928; 1981 (4⿳亠口冋 edic. e $2^{2}$ revisión).

- 1995. Los tipos del cuento folklórico. Una clasificación (trad. española de F. Peñalosa). Helsinki: Academia Scientiarum Fennica.

AZKUE, RESURRECCIÓN Ma․ 1989. Euskaleriaren Yakintza-Literatura popular del País Vasco. Bilbao-Madrid: Euskaltzaindia-Espasa Calpe. 4 volúmenes (1 $1^{\mathrm{a}}$ ed. 1935-1947).

BÉDIER, JEAN. 1969. Les Fabliaux. Études de littérature populaire et d'bistoire du moyen âge. París: Honoré Champion (1 $1^{\underline{a}}$ ed. 1893).

une non moins riche collection des petitions de principe et des paralogismes que la théorie orientaliste peut engendrer chez qui la manie sans faire un suffisant usage de son sens critique."

${ }^{23}$ Dice Espinosa (1947, II: 61) que: “El carácter oriental de todos estos cuentos salta a la vista. La inconstancia y la descarada infidelidad de las mujeres es un tema de carácter fundamentalmente oriental, que se manifiesta en todas las obras literarias de Oriente. El origen oriental de todos estos cuentos de Europa se sospechó en el momento que se conocieron las primeras versiones chinas en el siglo xviIr. 
BogGS, RalPH S. 1993. Index of Spanish Folktales. Helsinki: Academia Scientiarum Fennica, FF Communications, 90, 1930 ( $2^{\mathrm{a}} \mathrm{ed}$.).

BOUZA BREY, FERMín. 1946. "Miscelánea. Escritos no coleccionados de Rosalía de Castro, VI. Conto Gallegon. Cuadernos de Estudios Gallegos II: 281-290.

BRAga, TEÓfILO. 1995. Contos tradicionais do povo português. Dos volúmenes. Lisboa: Dom Quixote, edición de Ernesto Veiga de Oliveira (1ª ed. 1883).

Brenot, Alice (ed.). 1969. Phèdre. Fables. París: Société d'édition "Les Belles Lettres". BRUCKER, CHARLES. 1998. Les Fables de Marie de France, accompagnée d'une introduction, d'une traduction, de notes et d'un glossaire. París-Lovaina: Peeters.

CARDIGOS, ISABEL. Indice dos contos tradicionais portugueses (inédito).

CARRÉ Alvarellos, LoIs. 1968. Contos populares da Galiza. Oporto: Museu de Etnografía e História.

Carro RoQue, Ma Do Carmo. 1984. "Rosalía e a súa obra 'Conto gallego'”. Grial 85: 345-354.

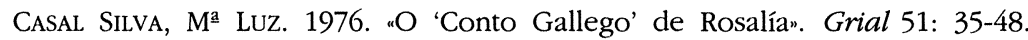

CHAmbry, Èmile. 1927. "Notice sur Esope e les fables ésopiques", Ésope. Fables. París: Societé d'Édition "Les belles lettres".

CheVAlIER, MAXIME. 1982. Tipos cómicos y folklore (siglos XVI y XVII). Madrid: Edi-6, 1982.

- (ed.). 1982b. Cuentos españoles de los siglos XVI y XVII. Madrid: Taurus.

COElHO, ADOLFO. 1879. Contos populares portugueses. Lisboa. $4^{\mathrm{a}}$ edición. Lisboa: Dom Quixote, 1995.

CURTIUS, ERNEST ROBERT. 1976. Literatura europea y Edad Media latina, 2 vols. México: FCE. Traducción al castellano de Margit Frenk Alatorre y Antonio Alatorre.

Delarve, PAUl y Ma LOUISE TÉNÈZe. 2002. Le conte populaire français. Catalogue raisonné des versions de France. Paris: Maisonneuve et Larose.

DUARTE TORNER, ANNA M". 1982. "Introducción", a Fedro y fábulas latinas de todos los tiempos. Reus (Tarragona): Ediciones Avesta.

ESPINOSA, Aurelio M. 1946-1947. Cuentos populares españoles, 3 vols. Madrid: CSIC. (1 $1^{\mathbf{a}}$ ed. 1923-1926).

Fernandes Trancoso, Gonzalo. 1585. Contos e Histórias de Proveito e Exemplo. Lisboa. De 1974, hay una edición de la Imprensa Nacional-Casa da Moeda.

FERNÁNDEZ Insuela, ANTONIO. 1993. "Cuentos de la tradición oral de Orense". Boletín Avriense XXII: 149-195.

Fabliaux. 2003. Los Fabliaux, edición bilingüe francés-castellano de J. López Alcaraz. Volumen tercero. Murcia: Universidad de Murcia.

"Fabulario português". 1903. Revista Lusitana VIII ( 2). Edición de Leyte de Vasconçelos.

Fábulas completas de Esopo-Fedro-La Fontaine-Iriarte y Samaniego. 1934. Madrid: Librería Bergua, versión española íntegra y nueva de Ángel Pumarega. 2 vols.

Fedro y fábulas latinas de todos los tiempos. 1982. Introducción y traducción por A. $M^{\mathrm{a}}$ Duarte Torner. Reus (Tarragona): Ediciones Avesta.

FRENZEL, ElISABETH. 1976. Diccionario de argumentos de la literatura universal. Madrid: Gredos.

GonZÁlez SANZ, CARLOS. 1996. Catálogo tipológico de cuentos de cuentos folklóricos aragoneses. Zaragoza: Instituto Aragonés de Antropología.

KRÖMER, WOLFRAM. 1979. Formas de la narración breve en las literaturas románicas basta 1700. Madrid: Gredos (1 ${ }^{\mathrm{a}}$ ed. alemana Berlín: Erich Schmidt Verlag, 1973).

LACARRA, Ma JeSÚs. 1999. Introducción a Cuento y novela corta en España I, Edad Media. Barcelona: Crítica. 
LÓPEZ AlCARAz, Josefa (ed.). 2003. Los Fabliaux, edición bilingüe francés-castellano, volumen tres. Murcia: Universidad de Murcia.

LÓPEZ VAlLEDOR, FANNY. 1999. Literatura de tradición oral nos Coutos (Ibias). A CaridáEl Franco: Xeira.

MARIE De France. 1998. Les Fables. Édition critique de Charles Brucker, accompagnée d'une introduction, d'une traduction, de notes et d'un glossaire. París-Lovaina: Peeters.

Noia CAMPOS, CAmiÑo. 2002. Contos galegos de tradición oral. Vigo: Nigratrea.

- 2003. Cuentos gallegos de tradicción oral. Vigo: Nigratrea. Traducción al castellano de Gonzalo Allegue de una selección de cuentos.

- 2004. "Contribución ao estudo das fontes do "Conto gallego", en Homenaxe ao profesor Fernando Tato. Santiago de Compostela: Fundación Barrié de la Maza-Instituto da Lingua Galega.

NyKrog, Per. 1957. Les Fabliaux. Étude d'bistoire littéraire et de stylistique médiévale. Copenhague.

ORIOL, CARMEN y JOSEP PUjOL. 2003. Index tipològic de la rondalla catalana. Barcelona: Generalitat de Catalunya, Departament de Cultura.

Petronio. 1991. Satiricón. Santiago de Compostela: Xunta de Galicia, colección “Clásicos en galego".

Lugo. 1963. Contos populares da provincia de Lugo. Vigo: Galaxia.

Phèdre. Fables. 1969. Texte établi et traduit par Alice Brenot. París: Société d'édition "Les Belles Lettres".

PINON, ROgER. 1965. El cuento folklórico como tema de estudio. Buenos Aires: Eudeba. Prieto, Laureano. 1958. Contos vianeses. Vigo: Galaxia.

Ríos PANISSE, M. C. 1995. "Contos da miña terra (1864), primeira edición do Conto gallego atribuido a Rosalía de Castro". Grial 126: 257-280.

- 1999. "A orixe popular de Contos da miña terra (Conto gallego), obra atribuída a Rosalía de Castron, en Homenaxe ó Profesor Camilo Flores: 606-625. Santiago de Compostela: Universidade de Santiago de Compostela.

RODRíguez AdRAdOS, Francisco. 1979. Historia de la fábula greco-latina. Madrid: Editorial de la Universidad Complutense, 3 vols.

- 1994. El cuento erótico griego, latino e indio. Madrid: Ediciones del Orto.

SAlISBURY, JOHANES DE. 1984. Policraticus (sive de nugis curialium et vestigiis philosophorum), edición castellana preparada por Miguel Ángel Ladero, Matías García e Tomás Zamarriego. Madrid: Editora Nacional.

ThEMA. Thesaurus Exemplorum Medii Aevi. Centre de Recherches historiques, CNRSEHESS, París (http//www.ehess.fr/gahom/thema/).

THOMPSON, STITH. 1955-1958. Motif-lndex of Folk Literature: a classification of narrative elements in folktales, ballads, miths, fables, mediaeval romances, exempla, fabliaux, jest-books and local legends (6 vols.). Copenhagen and Bloomington: Indiana University Press.

TubaCH, Frederic C. 1981. Index Exemplorum. A Handbook of Medieval Religious Tales. Helsinki: Academia Scientiarum Fenica.

UtHER, HANS-JÖRG. 2004. The Types of International Folktales. A Classification and Bibliography. Helsinki: Editorial Staff.

Versiones castellanas del Sendebar. 1946. Edición de Á. González Palencia. MadridGranada: CSIC. 